\title{
The alpha-smooth muscle actin promoter: a useful tool to analyse autocrine and paracrine roles of mesenchymal cells in normal and diseased bowel
}

Wang J, Niu W, Nikiforov Y, et al. Targeted overexpression of IGF-I evokes distinct patterns of organ remodeling in smooth muscle cell tissue beds of transgenic mice. f Clin Invest 1997;100:1425-39.

\section{Abstract}

Smooth muscle cells (SMC) of the vascular wall, bladder, myometrium, and gastrointestinal and respiratory tracts retain the ability to proliferate postnatally, which enables adaptive responses to injury, hormonal, or mechanical stimulation. SMC growth is regulated by a number of mesenchymal growth factors, including insulin-like growth factor I (IGF-I). To explore the function of IGF-I on SMC in vivo, the mouse SMC $\alpha$-actin promotor fragment SMP8 ( $-1074 \mathrm{bp}, 63 \mathrm{bp}$ of 5'UT and $2.5 \mathrm{~kb}$ of intron 1) was cloned upstream of rat IGF-I cDNA, and the fusion gene microinjected into fertilized eggs of the FVB-N mouse strain. Mating of hemizygous mice with controls produced about $50 \%$ transgenic offspring, with equal sex distribution. Transgenic IGF-I mRNA expression was confined to SMC-containing tissue, with the following hierarchy: bladder $>$ stomach $>$ aorta $=$ uterus $>$ intestine. There was no transgene expression in skeletal muscle, heart, or liver. Radioimmunoassayable IGF-I content was increased by 3.5- to 4-fold in aorta, and by almost 10-fold in bladder of transgenic mice at 5 and 10 wk, with no change in plasma IGF-I levels. Wet weight of bladder, stomach, intestine, uterus, and aorta was selectively increased, with no change in total body or carcass weight of transgenic animals. In situ hybridization showed that transgene expression was exquisitely targeted to the smooth muscle layers of the arteries, veins, bladder, ureter, stomach, intestine, and uterus. Paracine overproduction of IGF-I resulted in hyperplasia of the muscular layers of these tissues, manifesting in remarkably different phenotypes in the various SMC beds. Whereas the muscular layer of the bladder and stomach exhibited a concentric thickening, the SMC of the intestine and uterus grew in a longitudinal fashion, resulting in a marked lengthening of the small bowel and of the uterine horns. This report describes the first successful targeting of expression of any functional protein capable of modifying the phenotype of SMC in transgenic mice. IGF-I stimulates SMC hyperplasia, leading to distinct patterns of organ remodeling in the different tissue environments.

\section{Comment}

IGF-I AND NORMAL OR ADAPTIVE GROWTH OF BOWEL

IGF-I mediates many of the postnatal growth promoting actions of pituitary derived growth hormone $(\mathrm{GH})$ on multiple organs between birth and puberty and during adulthood. ${ }^{12}$ The bowel is now well established as an important target organ for GH and IGF-I. ${ }^{12} \mathrm{GH}$ and IGF-I are currently being used in clinical trials to improve bowel function in patients with short bowel syndrome. ${ }^{3} 4$ IGF-I seems to mediate many of the enterotrophic actions of $\mathrm{GH}$, which in turn increases circulating concentrations and local expression of IGF-I in bowel. ${ }^{25}$ Previous studies in transgenic mice overexpressing metallothionen promoter I driven human IGF-I transgenes (MT-hIGF-I mice) or bovine GH transgenes (MT-bGH mice) revealed major increases in the mass of intestinal mucosa and in small bowel length relative to wild type. ${ }^{56} \mathrm{MT}-\mathrm{hIGF}-\mathrm{I}$ mice have elevated circulating IGF-I, local overexpression of IGF-I in intestine and GH deficiency. ${ }^{6}$ Despite the deficiency in GH, MT-hIGF-I mice show similar or increased bowel growth compared with $\mathrm{MT}-\mathrm{bGH}$ mice that have excess GH and IGF-1. ${ }^{6}$ Although studies on MT-bGH and MT-hIGF-I mice support the concept that IGF-I mediates most of the enterotrophic actions of $\mathrm{GH}$, they did not tackle a key issue in IGF-I physiology - that is, the relative contributions of circulating versus locally expressed IGF-I in mediating bowel growth. A further limitation of the MT-hIGF-I mice is that the IGF-I transgene is expressed primarily in intestinal epithelial cells which are not the normal sites of endogenous IGF-I expression in bowel. ${ }^{6}$ A number of lines of evidence indicate that locally expressed, endogenous IGF-I contributes to normal or adaptive growth of bowel and is expressed throughout human and rodent bowel. ${ }^{78}$ Increased IGF-I expression in small bowel correlates with adaptive growth of bowel mucosa in response to refeeding ${ }^{9}$ or bowel resection, ${ }^{10} 11$ and correlates with increased growth of mucosa and enteric smooth muscle after myenteric denervation. ${ }^{12}$ Mesenchymal cells within the lamina propria or external smooth muscle layers seem to be the major sites of local expression of endogenous IGF-I in normal bowel in vivo. ${ }^{8}{ }^{12}$ Wang et al's study provides direct evidence that locally produced IGF-I can exert autocrine/ paracrine effects and increase the mass of external smooth muscle layers and small bowel length. That locally expressed IGF-I increases bowel length postnatally may be particularly relevant to patients with short bowel syndrome. ${ }^{13}$ Systemic IGF-I increases bowel length ${ }^{14}$ but the effects are less dramatic than observed in SMP8-IGF-I, MT-hIGF-I or MT-bGH mice. ${ }^{56}$ This difference may reflect duration of IGF-I excess or may indicate particularly potent effects of locally expressed IGF-I on bowel length. It is not clear whether increased proliferative activity of SMC in external smooth muscle layers or increased proliferative activity within mucosal SMC or mucosal epithelium, or both, increases bowel length. After bowel resection, humans or animal models show more dramatic, adaptive increases in mucosal thickness than in bowel length or thickness of muscularis propria, ${ }^{13}{ }^{15} 16$ which may favour SMC in muscularis propria as major determinants of bowel length. Future analyses of adaptive growth of 
bowel after resection in SMP8-IGF-I mice and possibly other transgenic models (yet to be developed) with targeted overexpression of IGF-I in mucosal epithelium could resolve this issue.

AUTOCRINE AND PARACRINE EFFECTS OF MESENCHYMAL CELL DERIVED IGF-I OR OTHER GROWTH FACTORS

During embryonic development, the intestinal mesenchyme underlying the mucosal epithelium is essential for normal morphogenesis, growth, and differentiation of intestinal epithelium. ${ }^{18}$ Several growth factors, including IGF-I, are expressed in intestinal mesenchyme. ${ }^{8} 91819$ Evidence for paracrine effects of specific factors derived from mucosal mesenchymal cells on growth of intestinal epithelium in vivo, particularly in the postnatal period, is largely indirect. ${ }^{891819}$ SMC in muscularis mucosa and SMC or myofibroblasts in the pericryptal region or villus core of the lamina propria express $\alpha$-smooth muscle actin (QSMA). ${ }^{17} 1820$ Overexpression of IGF-I within these mucosal mesenchymal cells would therefore be predicted in SMP8-IGF-I mice. Wang et al reported high level expression of the SMP8-IGF-I transgene in external smooth muscle layers. More detailed and higher resolution in situ hybridisation histochemistry analysis will be required to determine whether the transgene is also overexpressed in mucosal mesenchymal cells. If yes, the SMP8-IGF-I transgenic model could be used to assess whether IGF-I expressed in mucosal mesenchymal cells has paracrine effects on neighbouring mucosal epithelium. Wang et al reported no major difference in thickness of the small bowel mucosa in SMP8-IGF-I mice compared with wild type but this was the only measure of mucosal growth evaluated. Additional, more detailed studies are required in small bowel and other bowel segments to establish whether SMP8-IGF-I mice show increased crypt cell proliferation or altered differentiated function of mucosal epithelial cells.

Few promoters are currently available that permit cell specific targeting of transgenes within bowel. The available data in SMP8-IGF-I mice indicate that the $\alpha$ SMA promoter could be used to target overexpression of other growth factors to intestinal SMC and to analyse their autocrine actions on SMC growth and bowel length or function. If the SMP8-IGF-I mice do show altered growth or function of the mucosa, this would indicate that $\alpha$ SMA promoter mediated targeting of transgenes could be a generally useful approach to elucidate the role of specific growth factors in mediating mesenchymal/epithelial interactions within the bowel mucosa.

\section{USE OF THE QSMA PROMOTER TO TARGET GROWTH FACTOR INHIBITORS}

The "gain of function" approach offered by overexpression of transgenes, even those targeted to specific cells, is always subject to the criticism that excessively high or long term overexpression may not truly reflect the physiological function of the expressed protein. This is a potential problem with SMP8-IGF-I mice. In the future the $\alpha$ SMA promoter may, however, be used to target inhibitors of IGF-I action as a complementary approach to targeted IGF-I overexpression. Targeting IGF inhibitors of intestinal mesenchymal cells could provide major insights into the role of endogenous, mesenchymal cell derived IGF-I in mediating bowel growth. A family of natural IGF binding proteins (IGFBPs) exists, a subset of which can inhibit IGF action. ${ }^{1}$ Drs Wang and Fagin have already developed a transgenic model with SMP8 mediated targeting of one IGFBP, IGFBP $4 .{ }^{21}$ Preliminary data are encouraging and indicate a reverse phenotype in this model relative to SMP8-IGF-1 mice. ${ }^{21}$ There is one potential caveat to the use of the aSMA promoter to target growth factor inhibitors. As pointed out by Wang et al the aSMA promoter is active throughout embryogenesis and is expressed in cardiac and skeletal muscle in early embryogenesis. Despite this, there was no obvious phenotype of the SMP8-IGF-I transgene at birth. This probably reflects the fact that endogenous IGF expression is very high in the fetus and its effects are probably already maximal during embryonic development. When targeting growth factor inhibitors, or even other growth factors, the early expression of the $\alpha$ SMA promoter in cardiac and skeletal muscle or expression in fetal SMC may induce an embryonic phenotype or may complicate the phenotype relative to that observed for IGF-I.

IGF-I AND BOWEL DISEASE

Accumulating evidence implicates IGF-I as a mediator of mesenchymal cell responses to bowel inflammation and associated fibrogenic complications. ${ }^{22}$ IGF-I expression is increased locally in areas of fibrosis in the bowel of several animal models of entercolitis and in involved bowel of patients with Crohn's disease. ${ }^{22}$ Fibrosis is a major complication and cause of bowel surgery and short bowel syndrome in patients with Crohn's disease. ${ }^{1322}$ The precise cell type that mediates fibrosis in experimental enterocolitis or Crohn's disease has not been defined, but there is general agreement that these cells express $\alpha$ SMA, suggesting a SMC or myofibroblast phenotype. ${ }^{22}$ A subset of $\alpha$ SMA positive cells are the cellular sites of increased IGF-I expression in bowel of animal models of inflammation induced fibrosis. ${ }^{22}$ The SMP8-IGF-I mice thus show IGF-I overexpression in the precise cell types implicated in inflammation induced fibrosis and may be useful to assess whether constitutive overexpression of IGF-I in $\alpha$ SMA positive cells exacerbates fibrosis associated with experimental entercolitis. The complementary models such as the SMP8-IGFBP4 mice or mice with SMP8 mediated targeting of other IGF inhibitors could also be extremely powerful models to elucidate the extent to which endogenous IGF-I mediates inflammation induced fibrosis. As with adaptive growth, insightful results with the SMP8-IGF-I mice would indicate that the $\alpha$ SMA promoter may have widespread application to analysis of the roles of other factors in mesenchymal responses to inflammation in bowel or other organs.

P K LUND

Department of Physiology and

Center for Gastrointestinal Biology and Disease,

University of North Carolina, CB\#7545,

Chapel Hill, North Carolina 27599-7545, USA

1 Jones JI, Clemmons DR. Insulin-like growth factors and their binding proteins: biological actions. Endocr Rev 1995;16:3-34.

2 Lund PK. Insulin-like growth factors. In Dockray G, Walsh JH, eds. Gut peptides: biochemistry and physiology. New York: Raven Press, 1994:587-613.

3 Byrne TA, Morrissey TB, Nattakom TV, et al. Growth hormone, glutamine, and a modified diet enhance nutrient absorption in patients with severe short bowel syndrome. FPEN f Parenter Enteral Nutr 1995;19:296-302.

4 Byrne TA, Persinger RL, Young LS, et al. A new treatment for patients with short-bowel syndrome. Growth hormone, glutamine, and a modified diet. Ann Surg 1995;222:243-54.

5 Ulshen MH, Dowling RH, Fuller CR, et al. Enhanced growth of small bowel in transgenic mice overexpressing bovine growth hormone. Gastroenterology 1993;104:973-80.

6 Ohneda K, Ulshen MH, Fuller CR, et al. Enhanced growth of small bowel in transgenic mice expressing human insulin-like growth factor I. Gastroenterology 1997;112:444-54

7 Lund PK, Moats-Staats BM, Hynes MA, et al. Somatomedin-C/insulin-like growth factor-I and insulin-like growth factor-II mRNAs in rat fetal and adult tissues. F Biol Chem 1986;261:14539-44.

8 Han VK, D'Ercole AJ, Lund PK. Cellular localization of somatomedin (insulin-like growth factor) messenger RNA in the human fetus. Science 1987;236:193-7.

9 Winesett DE, Ulshen MH, Hoyt EC, et al. Regulation and localization of the insulin-like growth factor system in small bowel during altered nutrient status. Am F Physiol 1995;268: G631-40.

10 Mantell MP, Ziegler TR, Adamson WT, et al. Resection-induced colonic adaptation is augmented by IGF-I and associated with upregulation of colonic IGF-I mRNA. Am f Physiol 1995;269:G974-80.

11 Mantell MP, Ziegler TR, Smith RJ, et al. Regulation of the intestinal insulinlike growth factor (IGF-I) action pathway after massive small bowel reseclike growth factor (IGF-I) action pathway after massive smal
tion and IGF-I administration. Surg Forum 1993;44:1-4.

12 Mohapatra NK, Ulshen MH, Fuller CR, et al. Cell specific expression and regulation of insulin-like growth factor I (IGF-I) and IGF binding proteins 
(IGFBPs) during adaptive growth of small intestine [abstract]; 1995 Jun 14-17; Washington, DC. Bethesda, MD: The Endocrine Society Press, 995:OR37-5.

13 Thompson JS, Lagnas AN, Pinch LW, et al. Surgical approach to short-bowel syndrome: experience in a population of 160 patients. Ann Surg 1995;222:600-7.

14 Steeb CB, Trahair JF, Tomas FM, et al. Prolonged administration of IGF peptides enhances growth of gastrointestinal tissues in normal rats. Am $\mathcal{F}$ Physiol 1994;266:G1090-8.

15 Scott RB, Sheehan A, Chin BC, et al. Hyperplasia of the muscularis propria in response to massive intestinal resection in rat. F Pediatr Gastroenterol Nutr 1995;21:399-409.

16 Benhamou PH, Canarelli JP, Richard S, et al. Human recombinant growth hormone increases small bowel lengthening after massive small bowel resection in piglets. F Pediatr Surg 1997;32:1332-6.

17 Kedinger M, Simon-Assmann P, Bouziges F, et al. Smooth muscle actin expression during rat gut development and induction in fetal skin fibroblastic cells associated with intestinal embryonic epithelium. Differentiation 1990;43:87-97.

18 Fritsch C, Simon-Assmann P, Kedinger M, et al. Cytokines modulate fibroblast phenotype and epithelial-stroma interactions in rat intestine. Gastroenterology 1997;112:826-38.

19 Sonnenberg E, Meyer D, Weidner KM, et al. Scatter factor/hepatocyte growth factor and its receptor, the c-met tyrosine kinase, can mediate a signal exchange. 7 Cell Biol 1993;123:223-35.

20 Sappino AP, Dietrich PY, Skalli O, et al. Colonic pericryptal fibroblasts. Virchows Arch 1989;415:551-7.

21 Wang J, Niu W, Nikiforov YE, et al. Overexpression of IGFBP-4 through a SM $\alpha$ actin-IGFBP4 fusion gene leads to smooth muscle hypoplasia in transgenic mice [abstact]; 1997 Jun 11-14; Minneapolis, MN. Bethesda, MD: The Endocrine Society Press, 1997:OR25-3.

22 Lund PK, Zimmermann EM. Insulin-like growth factors and inflammatory disease. Baillieres Clin Gastroenterol 1996;10:83-96. 